\title{
The design features of cemented femoral hip implants
}

\author{
T. Scheerlinck, \\ P.-P. Casteleyn \\ From the Vrije \\ Universiteit Brussel, \\ Brussels, Belgium
}

- T. Scheerlinck, MD,

Orthopaedic Surgeon,

Associate Clinical Professor

In.-P. Casteleyn, $\mathrm{MD}, \mathrm{PhD}$,

Professor, Chairman of

Orthopaedic Surgery

Department of Orthopaedic and

Trauma Surgery

Academic Hospital of the Vrije

Universiteit Brussel,

Laarbeeklaan 101, 1090

Brussels, Belgium.

Correspondence should be sent to $\mathrm{Dr}$ T. Scheerlinck; e-mail:

Thierry.Scheerlinck@az.vub.ac. be

(C)2006 British Editorial Society of Bone and Joint Surgery doi:10.1302/0301-620X.88B11. $17836 \$ 2.00$

$J$ Bone Joint Surg [Br]

2006;88-B:1409-18.

\begin{abstract}
We undertook a review of the literature relating to the two basic stem designs in use in cemented hip replacement, namely loaded tapers or force-closed femoral stems, and the composite beam or shape-closed designs. The associated stem fixation theory as understood from in vitro studies and finite element modelling were examined with reference to the survivorship results for each of the concepts of fixation.

It is clear that both design principles are capable of producing successful long-term results, providing that their specific requirements of stem metallurgy, shape and surface finish, preparation of the bone and handling of the cement are observed.
\end{abstract}

Since the advent of cemented stem fixation in the early 1960s, surgical techniques and the design of implants have evolved dramatically. Some of these changes have resulted in improved survival while others have not. ${ }^{1,2}$ Mechanical studies in vitro and mathematical simulations with finite-element analysis are essential in evaluating the function of hip implants. However, predictions based entirely on these findings have not always been successful, illustrating the complexity of the interactions involved in the loosening of a cemented stem and the difficulty of reproducing the reallife situation. ${ }^{1,2}$

We have reviewed the different surface characteristics of implants, the shapes of the stem and the various options in geometrical stembroach sizing which have been adopted in an attempt to improve survival. In order to determine which of these combinations are satisfactory, experimental data have been related to clinical evidence of long-term success. The understanding of these concepts may help in the selection of potentially successful implants and of operative techniques.

\section{Stem philosophies}

The optimal shape of a stem should transmit torsional as well as axial load to the cement and to the bone without creating damaging peak stresses and without excessive micromovement. The stem should remain mechanically stable in the long term despite being subjected to repetitive loading. Two methods have been adopted to achieve these goals: 'loaded-taper' or 'force-closed' fixation and 'composite-beam'or 'shaped-closed' fixation ${ }^{3,4}$ (Fig. 1).

In the loaded-taper model epitomised by the Exeter implant (Stryker, Mahwah, New Jersey), the stem is tapered in two (CPT, Zimmer, Warsaw, Indiana) or three planes (Cstem, DePuy International Ltd., Leeds, United Kingdom) and becomes lodged as a wedge in the cement mantle during axial loading, ${ }^{5-7}$ reducing peak stresses in the proximal and distal cement mantle. ${ }^{8}$ The stem is allowed to subside initially until "radial compressive forces are created in the adjacent cement and transferred to the bone as hoop stress". An air-filled distal centraliser is used to facilitate subsidence of the stem to a stable position without creating excessive stresses in the distal cement mantle. ${ }^{9}$

In the composite-beam concept, the stem needs to be rigidly bound to the cement since subsidence or impairment of the stem-cement interface may result in damage to the cement, with the generation of polymethylmethacrylate (PMMA) and/or metal debris and ultimately failure of the implant. ${ }^{10}$ Because these implants are not intended to subside, the presence of a void at the tip of the stem is considered to be detrimental since it weakens the cement mantle. Such voids can appear when air trapped by the implant in the recess meant to fix the distal centraliser undergoes thermal expansion during curing of the cement. For that reason, it is advised to always use a distal centraliser when such a hole in the stem is present or to plug that hole with the in-stem portion of the centraliser, a 


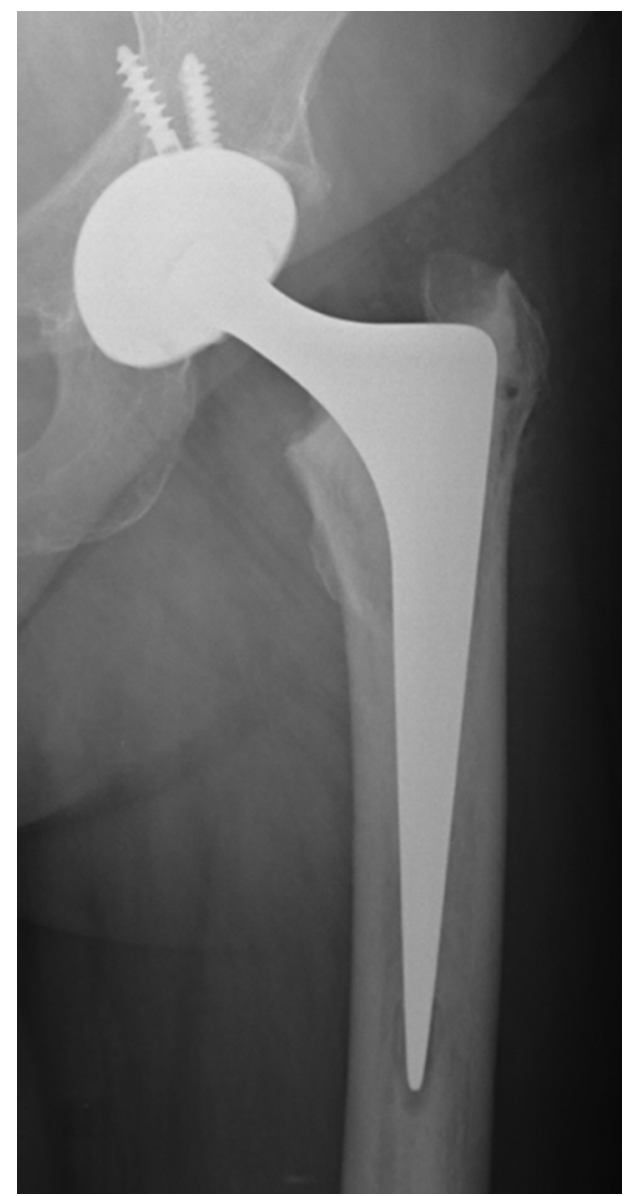

Fig. 1a

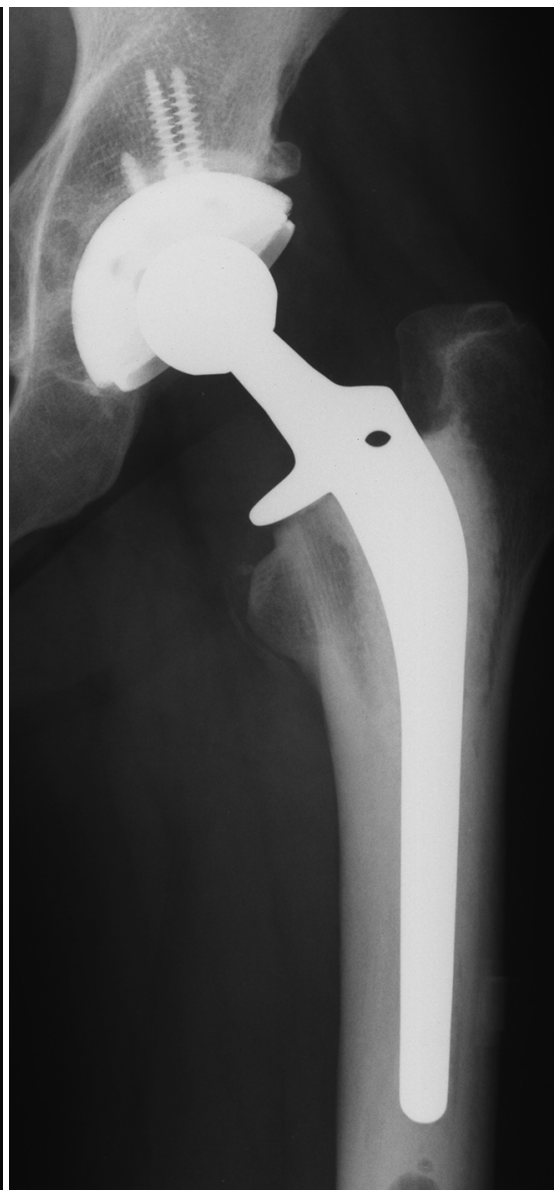

Fig. $1 b$

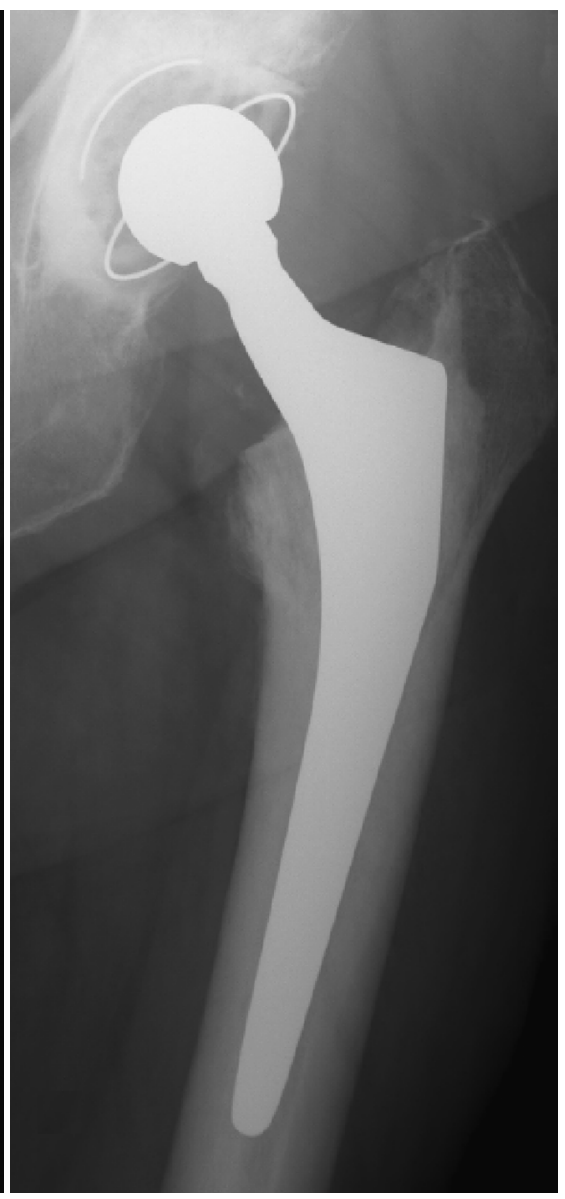

Fig. 1c

Radiographs showing stems of a) the loaded-taper type (CPT; Zimmer, Warsaw, Indiana) and b) the composite-beam type (Centralign, Zimmer) cemented undersized compared with the last broach, resulting in a thick cement mantle. Cementing a stem using a line-to-line technique gives a thin cement mantle and relies on c) the composite-beam fixation principle (Vectra; Biomet, Warsaw, Indiana).

plastic plug or cement which is allowed to cure before insertion of the stem. ${ }^{11-14}$

Loaded-taper and composite-beam stems behave differently in terms of migration over time when studied by radiostereometric analysis (RSA). Loaded-taper stems in the first year of implantation show initial migration with reported mean subsidence ranging from $0.9 \mathrm{~mm}$ to $1.4 \mathrm{~mm}$ and retroversion between $0.4 \mathrm{~mm}$ and $0.5 \mathrm{~mm} \cdot{ }^{3,7,15-19}$ After the initial year, these stems tend to stabilise. ${ }^{3,15,17}$ Initial migration seems to be independent of the type of cement, its viscosity ${ }^{17,18}$ and the thickness of the cement mantle. ${ }^{17}$ Although tapered implants tend to stabilise only secondarily, they remain relatively stable over time. ${ }^{7}$ The cement mantle surrounding these stems does not migrate, ${ }^{3,16,19}$ or does so only slightly ${ }^{7}$ within the femur, which does not appear to compromise the long-term results. However, the degree of long-term migration which loaded-taper stems can tolerate is not known. ${ }^{7}$

Stems relying on the composite-beam principle have more initial stability especially in the longitudinal direction with mean migration ranging between $0.1 \mathrm{~mm}$ and $0.5 \mathrm{~mm}$ during the first year. ${ }^{3,15,16,20,21}$ However, some tend to migrate also into retroversion, generally between $0.28 \mathrm{~mm}$ and $0.8 \mathrm{~mm},{ }^{15,20,21}$ but sometimes up to $1.0 \mathrm{~mm}$ and even $2.0 \mathrm{~mm}^{22,23}$ during the first year. In some instances migration at the cement-bone interface has also been seen. ${ }^{16,21,23}$ Both factors are worrying since excessive and continuous migration, ${ }^{23,24}$ may be considered to be predictive of failure..$^{20,22}$

\section{Stem philosophy and surface finish}

Polished stems are preferred with the loaded-taper design since they allow stepwise subsidence to a stable position, ${ }^{3,25}$ with the associated micromovement producing less metal and cement debris at the cement-stem interface. ${ }^{9,26,27}$ By contrast, in the composite-beam prostheses, it may be logical to optimise stability by roughening the surface to increase the cement-stem bonding.

Mechanical effect of the surface finish. From a mechanical perspective, a weak cement-stem bond with a polished stem 
Table I. Details of studies showing the relation between the surface finish of cemented femoral hip implants with a similar stem geometry and clinical outcome

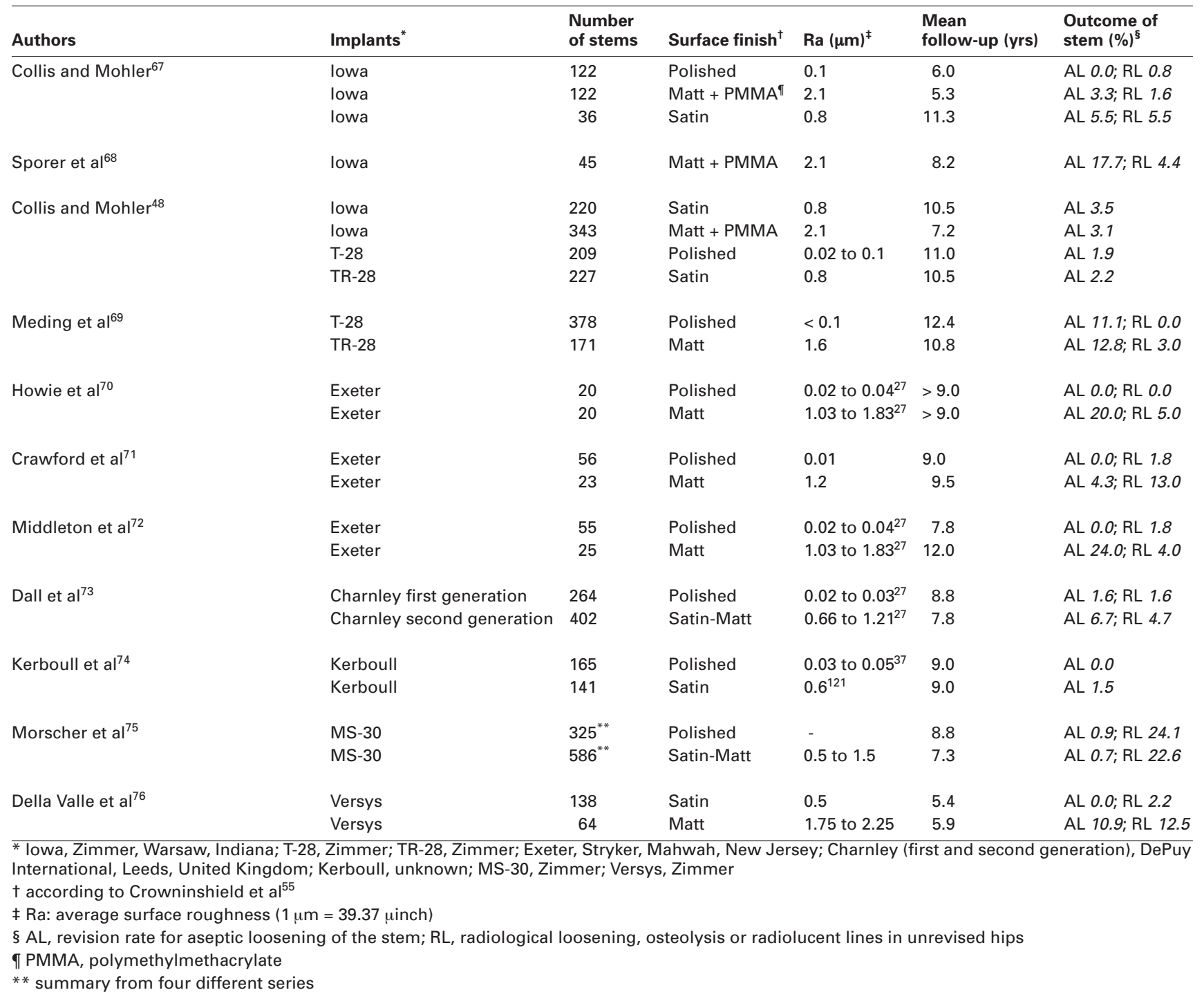

has little effect on the distal, but increases proximal, cement strains. ${ }^{28}$ When the cement-stem bond increases, compression stresses decrease, but higher tensile and shear stresses appear in the cement mantle and at the cement-bone interface. ${ }^{29}$ Poorly-bound polished stems do not create tensile stresses and decrease shear stresses in the cement and the cement-bone interface. ${ }^{29}$ In contrast to compression strains, which can be transmitted without a reliable cementstem bond, transmission of tensile strains relies largely on a good bond. ${ }^{30}$ Since this tensile bond may be unreliable over time, Crowninshield et $\mathrm{al}^{30}$ have suggested that "it is unwise to design prostheses that rely heavily on the presence of a good (stem-cement) bond". Moreover, because PMMA tolerates compressive loads well, but is more vulnerable to tensile stresses and shear forces, ${ }^{31}$ weakly-bound stems may load the cement in a less damaging way.
Failure of the implant due to accumulated mechanical damage to the cement-bone interface has been described both in vitro ${ }^{32}$ and in vivo. ${ }^{10,33,34}$ Because weakly-bound stems transfer less shear force and tensile stress to the cement-bone interface, that interface may be less damaged. ${ }^{29}$ This explains why implants with a strong cementstem bond may be more sensitive to the presence of incomplete and thin cement mantles with a poor cement-bone interface than polished stems. ${ }^{34-38}$

Wear and surface finish. Despite efforts to enhance the cement-stem bond by pre-coating or roughening of the stem, micromovement between the stem and cement seems to be inevitable. This is due to differences in elasticity between the stem, cement, cancellous and cortical bone and to the repetitive axial and torsional loads applied to the stem-cement-bone composite by the body-weight and by 


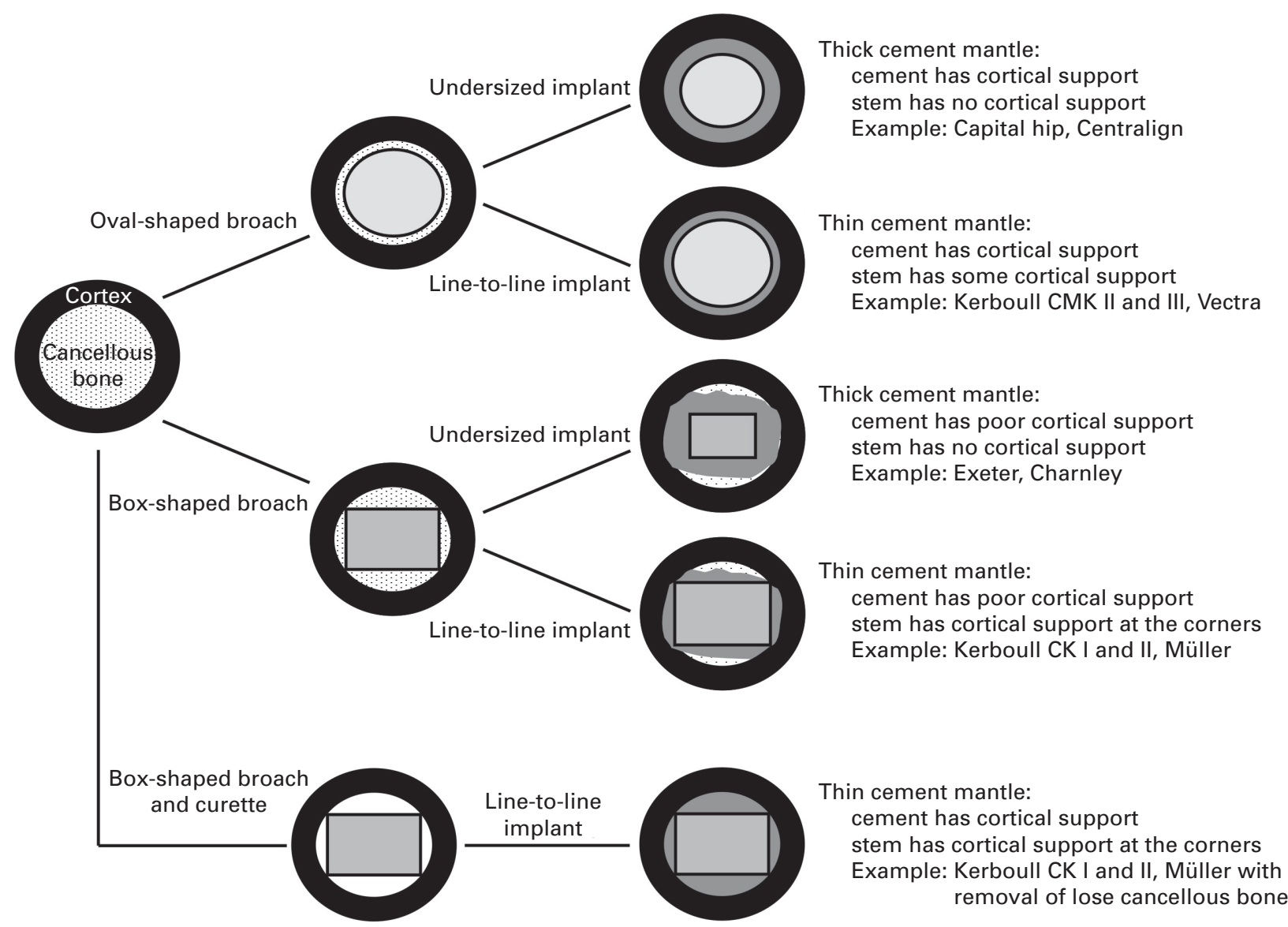

Fig. 2

Diagram showing the influence of the stem-broach matching and cross-sectional shape of the stem on the appearance of the cement mantle (Capital Hip, 3M Health Care Ltd, Loughborough, United Kingdom; Centralign, Zimmer, Warsaw, Indiana; Kerboull CMK II, Smith \& Nephew, Memphis, Tennessee; Kerboull CMK III, Vecteur Orthpédique, Marne la Vallée, France; Vectra, Biomet, Warsaw, Indiana; Exeter, Stryker, Mahwah, New Jersey; Charnley, DePuy International Ltd, Leeds, United Kingdom; Kerboull CK I, Stryker; Kerboull CK II, Stryker; Müller, Zimmer).

the action of the muscles on the proximal femur. ${ }^{39,40}$ Mechanical testing in vitro, ${ }^{41-44}$ as well as RSA studies in vitro and in vivo, ${ }^{35,45,46}$ have shown that perfect stability of the stem is improbable. When debonding finally occurs at the pre-coated or roughened cement-stem interface, there will be damage to the cement and large quantities of PMMA and/or metal particles will be generated ${ }^{25,47}$ causing osteolysis, loss of bony support and loosening of the implant. ${ }^{10,26,36,48-53}$ This seems less critical for polished stems because, compared with non-polished implants, gap formation at the cement-stem interface ${ }^{25}$ and migration of particles along that interface are reduced, ${ }^{54}$ and micromovement between the implant and cement produces less debris. ${ }^{25,27,47,55}$ Moreover, whereas unpolished stems become polished at the surface with release of debris, polished stems mostly show pitting, with retention of debris on their surface. ${ }^{27}$

Wear at the cement-stem interface will be even greater if unpolished stems, made of materials with less wearresistance such as titanium alloy, loosen. ${ }^{53,56-58}$ This may account for the poor performance of unpolished cemented titanium stems $33,51,56,59-63$ while polished or smooth cemented stems of this material have survived well. ${ }^{37,64-66}$

It can be concluded that 'rougher' stems need a thick, continuous cement mantle of good quality with a strong cement-bone interface and should be made of wearresistant materials, whereas polished stems may be more tolerant to suboptimal cementing and manufactured from less wear-resistant materials. This may also explain why the same design of stem but with a smoother surface finish performs better than its rougher equivalent, even if they are of the composite-beam design (Table I). ${ }^{48,67-76}$

Geometry of the stem. Several features of the shape of the stem influence the in vivo behaviour of femoral components, including the overall shape (straight or anatomical), the cross-section (oval or square), the presence of a collar, the shape of the tip of the stem, the length of the stem and whether the edges are rounded to a greater or lesser degree. Straight and anatomical stems. In contrast to symmetrical stems ${ }^{14}$ such as the Charnley (DePuy International Limited, 
Leeds, United Kingdom), Exeter (Stryker), Müller (Zimmer, Warsaw, Indiana), Versys (Zimmer) and Spectron (Smith \& Nephew, Memphis, Tennessee), anatomically-shaped components like the Lubinus SP2 (Waldemar Link GmbH, Hamburg, Germany), ABG (Stryker), Olympia (Biomet, Warsaw, Indiana), Aura II (Biomet), SHP (Biomet) and APR II (Zimmer) are designed to fit the sagittal intra-medullary anatomy ${ }^{77}$ This allows better centralisation of the stem and more even thickness of the cement mantle. ${ }^{78}$ Compared with symmetrical stems, anatomical stems generate different strains within the cement mantle because of their specific shape. ${ }^{79}$ They are of the shape-closed or compositebeam type since their shape limits the subsidence required to achieve a stable position. However, it remains questionable if these characteristics are key advantages since both types of stem have performed equally well in the long term. ${ }^{9,46,80-83}$ Nevertheless, an anatomical stem, which can be inserted more anteriorly in the shaft without creating an area of anterior proximal cortical contact and posterior distal point contact, could be an advantage, especially for the less experienced surgeon using an anterior approach.

The cross-sectional shape of the stem. The cross-sectional shape influences the distribution of cement within the femoral canal, the rotational stability of the implant ${ }^{84}$ and the stress distribution within the cement mantle. ${ }^{30}$ Broaches and stems with an oval cross-section as found in the Kerboull CMK II (Smith \& Nephew) and III (Vecteur Orthopédique, Marne la Vallée, France), Vectra (Biomet) and Centralign (Zimmer) have a better fit within the medullary canal and can occupy more of the cavity, leaving less room for cement and cancellous bone. By contrast, the broaches and stems with a more rectangular cross-section such as the Exeter (Stryker), CPT (Zimmer), CPS-plus (Endoplus, Swindon, United Kingdom) and the Kerboull CK I (Stryker), are limited in size by their contact against the inner cortex of the oval cross-section of the medullary canal. This may result in additional space for pressurisation of cement into the remaining cancellous bone beyond the reach of the broaches. However, if cement is not or cannot be fully pressurised into that layer, mechanically weak cancellous bone will be interposed between the cement and cortical bone. This can be avoided by removing this cancellous bone with a curette before cementing the stem, taking care to leave a minimal amount of well-fixed cancellous bone attached to the cortex to allow proper interdigitation of the cement (Fig. 2). Since modern cementing techniques allow pressurisation of cement into cancellous bone over a distance of $3 \mathrm{~mm},{ }^{85}$ that amount of remaining cancellous bone should be adequate.

Stems with a square cross-section offer more rotational stability than oval stems. However, sharp edges create peak stresses in the cement, which could lead to microfractures. Mann and $\mathrm{Kim}^{84}$ calculated, based on a finite-element model, that optimal rotational stability with acceptable peak stresses in the cement was obtained when the corners had a fillet radius of $2 \mathrm{~mm}$. In clinical practice, the original polished Charnley-Kerboull stem with a quadrangular cross-section performed better than a later matt version with an oval cross-section. ${ }^{37,86}$ However, it is unclear whether that underperformance could be attributed to the oval cross-section and/or the matt surface finish.

The addition of proximal anteroposterior cobra-shaped dorsal flanges to the stem has been advocated in order to decrease stress shielding, to enhance stability of the stem and to increase the interlock between the stem and the cement. ${ }^{87}$ However, dorsal flanges caused higher cementbone micromovement in vitro ${ }^{87}$ and are associated with more cement-bone radiolucencies in vivo ${ }^{60}$ In clinical practice, a dorsal flange reduced subsidence of the stem and the incidence of fractures of the distal cement. ${ }^{88}$ However, the survival rates of the flanged grit-blasted cobra-shaped Charnley stem at 15 and 25 years were less satisfactory than those of the non-flanged polished version. ${ }^{60}$ It is unclear if this was attributable to the flange, the rougher stem surface or to both.

In order to improve the rotational stability of polished tapered stems, the CPS-plus stem (Endoplus) was designed to fill the canal to a greater extent and had a broader shoulder and a more rectangular cross-section compared with the original Exeter stem (Stryker). Two years after implantation RSA confirmed a similar pattern of subsidence but with improved rotational stability and decreased valgus migration compared with the original Exeter design. ${ }^{89}$ This is expected to improve the long-term outcome but remains to be proven by clinical follow-up studies.

Geometry of the proximal stem. Experimental ${ }^{79,90-92}$ and finite-element analysis studies ${ }^{29,90,92,93}$ both found high focal strains in the cement mantle at the level of the medial femoral neck and/or near the tip of the implants. These regions are vulnerable to damage to the cement during initial loading. ${ }^{94}$ When cracks in the cement extend from the region of the medial femoral neck and from the tip of the stem over the complete length of the stem, failure of the implant is imminent. ${ }^{94}$ Therefore, it is important to reduce cement strains in these regions, and to obtain a cement mantle of good quality removing mechanically-weak cancellous bone between the cement and the cortex, especially in the region of the medial femoral neck. This last point has been supported by mechanical testing, ${ }^{95,96}$ finite-element analysis ${ }^{97}$ and clinical data. ${ }^{98-102}$

Theoretically, the collar of the cemented femoral component has two functions. First, it has the potential to promote direct transfer of load from the implant to the medial cement mantle and/or the bone of the medial femoral neck, at least when a close contact is achieved initially and maintained over time. Moreover, direct collar-bone contact can unload the vulnerable proximal cement mantle. ${ }^{91,103}$ The presence of a collar can also reduce tensile stresses in the stem ${ }^{104}$ and reduce overall migration. ${ }^{21,105}$ However, a collar has a negative effect on the final rate of migration, ${ }^{105}$ preventing the stem from 'settling' during cyclic loading, and does not avoid micromovement of the 
Table II. Stem-broach mismatch of different femoral stems according to a manufacturer's survey performed by us in 2002

\begin{tabular}{|c|c|c|c|}
\hline \multicolumn{2}{|c|}{ Stems > 1 mm undersized compared with broach } & \multicolumn{2}{|c|}{ Stems $\leq 1 \mathrm{~mm}$ undersized compared with broach } \\
\hline Brand $^{*}$ & Stem & Brand $^{*}$ & Stem \\
\hline Zimmer & СРТ & Zimmer & Metabloc \\
\hline Zimmer & Versys & Zimmer & Müller \\
\hline Zimmer & Harris & Zimmer & Exofit \\
\hline Zimmer & MS 30 & Zimmer & Weber \\
\hline DePuy & $\begin{array}{l}\text { Charnley, Elite/Elite } \\
\text { plus }\end{array}$ & DePuy & Modulor \\
\hline DePuy & C-stem & Céraver & Ostéal \\
\hline Stryker & Exeter & Stryker & Kerboull MK III \\
\hline Stryker & Contemporary hip & Stryker & Legend V40 \\
\hline Endoplus & CPS-Plus & Stryker & ABG cemented \\
\hline Biomet & Mallory Head interlock & Biomet & Vectra III \\
\hline Biomet & Stanmore & Biomet & Aura II \\
\hline Biomet & Answer, Alliance & SEM & SEM III \\
\hline Wright Medical & Helianthe & Wright Medical & PTC \\
\hline Smith \& Nephew & Spectron & Waldemar Link & Lubinus \\
\hline Smith \& Nephew & Synergy & Smith \& Nephew & CMK 21 \\
\hline
\end{tabular}

stem $^{105}$ or the production of wear debris from the cementstem interface. ${ }^{27}$ Neither does a collar prevent early resorption of the medial femoral neck, ${ }^{106-110}$ which could be due to debris generated by attrition of the collar against bone and cement, ${ }^{108}$ and could jeopardise the loading function of the medial femoral neck. A collar is also counter-productive in loaded-taper stems since they need to subside within the cement mantle to reach a stable final position. ${ }^{108}$

The second function of the collar is to control insertion, especially when the stem is undersized compared with the broach, so that the final implant is inserted to exactly the same level as the broach. For implants which are not undersized, this is not crucial since the stem will automatically be directed to the broach position by contact with the bone.

A collar should only be considered in composite-beam stems which are undersized compared with the broach. However, even then, survival of the stem has not been improved as demonstrated in series comparing the same geometry with and without a collar. ${ }^{111,112}$

Stem-broach mismatch. From a biomechanical ${ }^{92,97,113,114}$ and clinical ${ }^{99,115,116}$ point of view it has been recommended that a cement mantle which is subjected to high stresses should be between $2 \mathrm{~mm}$ and $5 \mathrm{~mm}$ thick, especially in the proximomedial part of the implant and around the tip of the distal stem. However, cement mantles thicker than $5 \mathrm{~mm}$ to $10 \mathrm{~mm}$ could increase micromovement and could be detrimental. ${ }^{99,113}$ Retrieval studies have reported more cracks in areas of thin cement. ${ }^{117}$ Mechanical and finiteelement studies of the propagation of fatigue cracks in the cement showed that the rate of growth of the crack was independent of the thickness of the cement mantle. ${ }^{114,118}$ However, cracks in thin cement reached full-thickness in fewer loading cycles. ${ }^{118}$ After loading of cemented stems, regions of thin cement $(<2 \mathrm{~mm})$ presented fewer cement cracks but more full-thickness cracks than the other regions. ${ }^{114}$ Finally, from a biological point of view fullthickness cracks together with defects in the cement constitute a possible pathway for migration of particles from the cement-stem interface to the bone. This could be a source of particle-induced osteolysis even in well-fixed implants. $26,38,119,120$

In order to favour a 'thick and flawless' cement mantle, some systems use stems which are undersized compared with the corresponding broach. However, in addition to these undersized stems most manufacturers also market stems which have the same size as the broach system and which are cemented 'line-to-line' (Table II).

Recently, the old debate concerning the appropriateness of undersizing the stem has been raised again by Langlais et $\mathrm{al}^{37,121}$ as the 'French paradox'. These authors, among others, ${ }^{64,86}$ have presented and reviewed excellent longterm results obtained with different polished and rectangular canal-filling stems cemented line-to-line after using the largest possible broach. These stems aim at a direct load transfer to bone by close cortical contact. As such, they are not meant to subside within the cement mantle and can be considered as 'shape-closed'. Comparing the results at ten years of the Freeman hip replacement, cemented line-to-line or undersized, Skinner et al ${ }^{122}$ concluded that a line-to-line technique "is not worse and may produce better long-term results than current teaching suggests". Müller ${ }^{123}$ reported similar findings, and 10 to 15 years after introducing his straight stem he noted that: "The closer the contact between the stem and the bone, the better were the results". Therefore, despite a potentially suboptimal cement mantle, some stems inserted line-to-line with the largest broach have performed very well clinically (Table III). ${ }^{66,74,86,100,122,124-128}$

Canal-filling stems offer many theoretical advantages. First, removal of a maximal amount of mechanically-weak 
Table III. Details of studies reporting results of femoral-canal-filling stems inserted with a minimal cement mantle

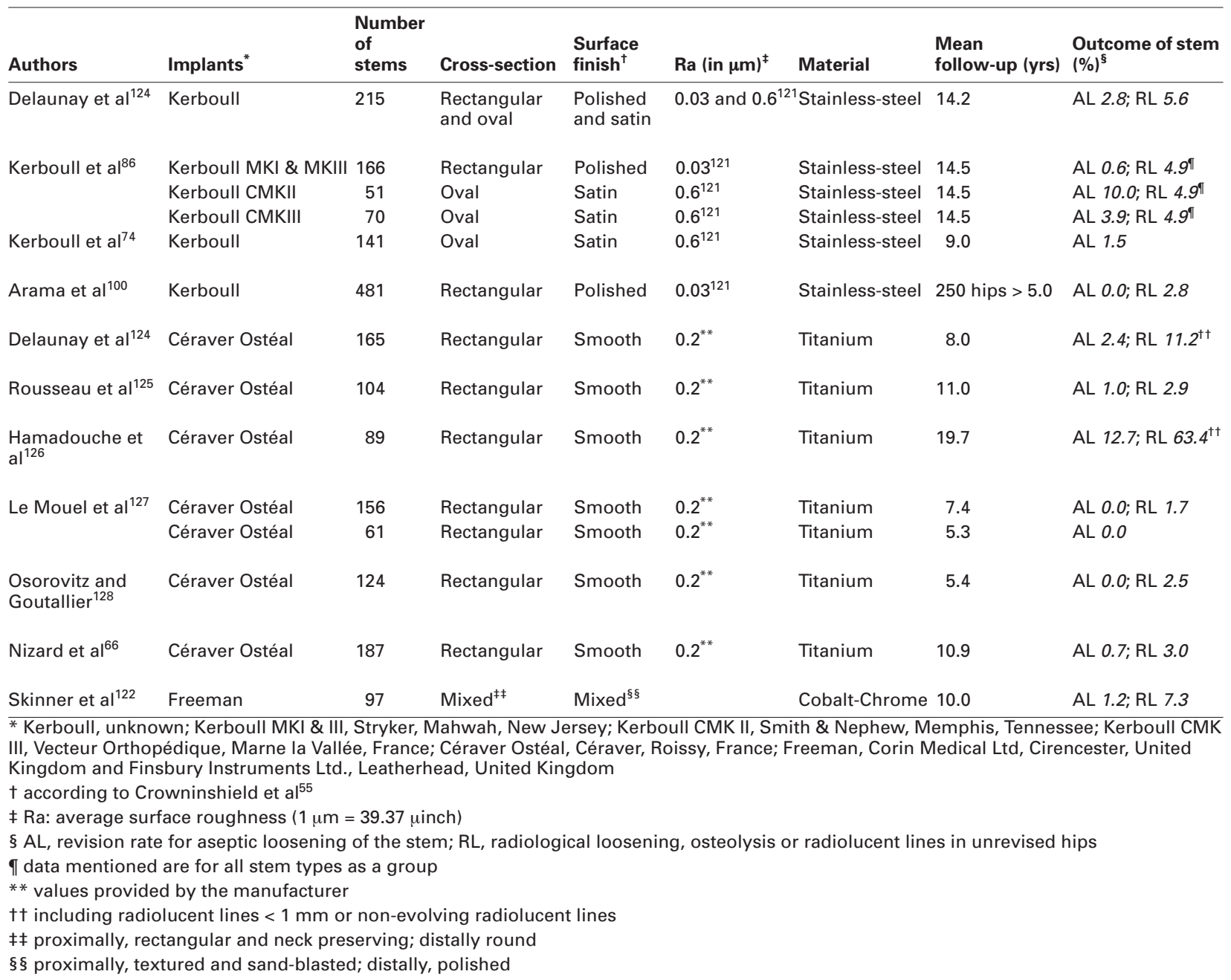

cancellous bone favours direct load transfer to the cortex. This occurs either through direct point contacts between the implant and cortical bone or through a thin cement layer between the implant and cortex without interposition of weak cancellous bone. This concept may improve the stability of the implant. ${ }^{29,30}$ Secondly, points of contact between implant and cortex could facilitate stem insertion by controlling stem alignment and insertion depth and by stabilising the implant during cement curing. Finally, insertion of a stem with similar dimensions as the largest possible broach creates high intramedullary cement pressures, ${ }^{129}$ which could favour interdigitation of the cement into the remaining cancellous bone and cement penetration up to the cortex. Since larger quantities of cancellous bone remain in the proximal part of the femur after broaching, the effect is more marked in that region. ${ }^{122}$ This could improve the quality of the cement mantle, especially if a suboptimal cementing technique is used without adequate pressurisation. Therefore it is possible that cemented line-to-line implants could be more 'user-friendly' for less experienced surgeons.
A recent study ${ }^{85}$ using CT and polymeric CharnleyKerboull replicas showed that these stems, when cemented line-to-line with the largest broach, created a cement mantle which averaged over $3 \mathrm{~mm}$ in thickness. Because of pressurisation of the cement into cancellous bone, defects $(<1 \mathrm{~mm}$ of cement thickness) were found in only $6 \%$ of the interface, but areas with a cement thickness $<2 \mathrm{~mm}$ were found in $26 \%$. These were noted mostly in the distal two-thirds and at the corners of the stem. Because areas of thin cement appeared to be supported mainly by cortical bone, they might be less detrimental than initially believed.

\section{Summary and conclusions}

Cemented femoral implants have been developed to function either as loaded-tapers or composite-beams. Stems of the loaded-taper type should be polished to favour stepwise subsidence to a stable position. They are very sensitive to a rough surface finish and are incompatible with the use of a collar as a positioning device, an anatomical shape or canal-filling design of the stem, since these features prevent subsidence within the cement mantle. 
A stem relying on the composite-beam principle can be either straight or anatomical. Both have proved to be equally successful. Composite beams can be achieved with the interposition of a thick or a thin layer of cement, depending on whether the implant is undersized compared with the broach or not. A canal-filling stem is cemented line-to-line with the size of the last broach used and stemcortex contact points as well as areas of thin cement supported by cortical bone help to stabilise the implant. In clinical practice, this user-friendly concept has been proved to work well.

In the composite-beam design the use of a rough surface finish to increase the stability of the stem seems to be logical but it can generate detrimental cement and metal debris when the inevitable micromovement of the stem appears. This is troublesome especially when a canal-filling stem is used, since particles will be allowed to migrate to the cement-bone interface through areas of cortical point contact and to create osteolysis. Additionally, a rough surface finish increases tensile and shear stresses in the cement mantle and at the cement-bone interface. This makes rougher stems less forgiving with suboptimal cementing conditions. Finally, a rough surface finish is not compatible with less wear-resistant materials such as titanium. In clinical practice, polished stems with a similar design were found to be more reliable in the long term compared with rougher stems and a smooth or polished surface finish should be favoured even for implants relying on the composite-beam principle.

Excessive and continuous migration of the implant is detrimental for both loaded-taper and composite-beam stems. However, it seems that implants of the loaded-taper type tolerate initial migration better and present a more stable cement mantle at the cement-bone interface. Composite-beam stems tend to be globally more stable, especially in the first years. However, in some cases, rotational instability may appear and excessive load transfer to the cement mantle may result in migration of the cement at the cement-bone interface. Both these phenomena are known to be predictors of poor longterm results.

Although in vivo both concepts of stem fixation have proved to be effective, they cannot work together. It is important to understand on which principle a particular stem relies.

\section{References}

1. Barrack RL. Early failure of modern cemented stems. J Arthroplasty 2000;15:103650

2. Huiskes R. Failed innovation in total hip replacement: diagnosis and proposal for a cure. Acta Orthop Scand 1993;64:699-716.

3. Huiskes R, Verdonschot N, Nivbrant B. Migration, stem shape, and surface finish in cemented total hip arthroplasty. Clin Orthop 1998;355:103-12.

4. Shen G. Femoral stem fixation: an engineering interpretation of the long-term outcome of Charnley and Exeter stems. J Bone Joint Surg [Br] 1998;80-B:754-6.

5. Wroblewski BM, Siney PD, Fleming PA. Triple taper polished cemented stem in total hip arthroplasty: rationale for the design, surgical technique, and 7 years of clinical experience. J Arthroplasty 2001;16(8 Suppl):37-41.

6. Ek ET, Choong PF. Comparison between triple-tapered and double-tapered cemented femoral stems in total hip arthroplasty: a prospective study comparing the $\mathrm{C}$-stem versus the Exeter Universal results after 5 years of clinical experience. J Arthroplasty 2005:20:94-100.
7. Stefansdottir A, Franzen H, Johnsson R, Ornstein E, Sundberg M. Movement pattern of the Exeter femoral stem: a radiostereometric analysis of 22 primary hip arthroplasties followed for 5 years. Acta Orthop Scand 2004;75:408-14.

8. Huiskes R, Boeklagen R. Mathematical shape optimization of hip prosthesis design. J Biomech 1989;22:793-804.

9. Williams HD, Browne G, Gie GA, et al. The Exeter universal cemented femoral component at 8 to 12 years: a study of the first 325 hips. J Bone Joint Surg [Br] 2002;84-B:324-34.

10. Ong A, Wong KL, Lai M, Garino JP, Steinberg ME. Early failure of precoated femoral components in primary total hip arthroplasty. J Bone Joint Surg [Am] 2002;84A:786-92.

11. Hanson PB, Walker RH. Total hip arthroplasty cemented femoral component distal centralizer: effect on stem centralization and cement mantle. J Arthroplasty 1995; 10:683-8.

12. Smith SG, Kabo JM, Kilgus DJ. Effects of distal femoral centralizers on bonecement in total hip arthroplasty: an experimental analysis of cement-centralizer bonding, cement void formation, and crack propagation. J Arthroplasty 1996;11:687-92.

13. Berger RA, Steel MJ, Schleiden M, Rubash HE. Preventing distal voids during cementation of the femoral component in total hip arthroplasty. J Arthroplasty 1993;8:323-9.

14. Berger RA, Seel J, Wood K, et al. Effect of a centralizing device on cement mantle deficiencies and initial prosthetic alignment in total hip arthroplasty. J Arthroplasty 1997; 12:434-43.

15. Alfaro-Adrian J, Gill HS, Murray DW. Should total hip arthroplasty femoral components be designed to subside: a radiostereometric analysis study of the Charnley Elite and Exeter stems. J Arthroplasty 2001;16:598-606.

16. Alfaro-Adrian J, Gill HS, Murray DW. Cement migration after THR: a comparison of Charnley Elite and Exeter femoral stems using RSA. J Bone Joint Surg [Br] 1999;81B:130-4.

17. Nelissen RG, Garling EH, Valstar ER. Influence of cement viscosity and cement mantle thickness on migration of the Exeter total hip prosthesis. $J$ Arthroplasty 2005;20:521-8

18. Glyn-Jones S, Hicks J, Alfaro-Adrian J, et al. The influence of cement viscosity on the early migration of a tapered polished femoral stem. Int Orthop 2003;27:362-5.

19. Ornstein E, Franzen H, Johnsson R, et al. Early subsidence of the Exeter femoral stem within the cement mantle in primary arthroplasties and in revisions using impacted allografts and cement: a roentgen stereophotogrammetric analysis. Hip Int 1999;9:139-43.

20. Alfaro-Adrian J, Gill HS, Marks BE, Murray DW. Mid-term migration of a cemented total hip replacement assessed by radiostereometric analysis. Int Orthop 1999;23:140-4.

21. Catani F, Ensini A, Leardini A, et al. Migration of cemented stem and restrictor after total hip arthroplasty: a radiostereometry study of 25 patients with Lubinus SP II stem. J Arthroplasty 2005;20:244-9.

22. Hauptfleisch J, Glyn-Jones S, Beard DJ, Gill HS, Murray DW. The premature failure of the Charnley Elite-Plus stem: a confirmation of RSA predictions. J Bone Joint Surg [Br] 2006;88-B:179-83.

23. Karrholm J, Borssen B, Lowenhielm G, Snorrason F. Does early micromotion of femoral stem prostheses matter: 4-7-year stereoradiographic follow-up of 84 cemented prostheses. J Bone Joint Surg [Br] 1994;76-B:912-17.

24. Kärrholm J, Herberts $\mathbf{P}$, Hultmark $\mathbf{P}$, et al. Radiostereometry of hip prostheses: review of methodology and clinical results. Clin Orthop 1997;344:94-110.

25. Verdonschot N, Huiskes R. Surface roughness of debonded straight-tapered stems in cemented THA reduces subsidence but not cement damage. Biomaterials 1998;19:1773-9.

26. Anthony PP, Gie GA, Howie CR, Ling RS. Localised endosteal bone lysis in relation to femoral components of cemented total hip arthroplasty. J Bone Joint Surg $[\mathrm{Br}]$ 1990;72-B:971-9.

27. Howell JR Jr, Blunt LA, Doyle C, et al. In vivo surface wear mechanisms of femoral components of cemented total hip arthroplasties: the influence of wear mechanism on clinical outcome. J Arthroplasty 2004;19:88-101.

28. Crowninshield RD, Tolbert JR. Cement strain measurement surrounding loose and well-fixed femoral component stems. J Biomed Mater Res 1983;17:819-28.

29. Massin P, Astoin E, Lavaste F. Influence of proximal stem geometry and stemcement interface characteristics on bone and cement stresses in femoral hip arthroplasty: finite element analysis. Rev Chir Orthop Reparatrice Appar Mot 2003;89:134-43 (in French).

30. Crowninshield RD, Brand RA, Johnston RC, Milroy JC. The effect of femoral stem cross-sectional geometry on cement stresses in total hip reconstruction. Clin Orthop 1980;146:71-7.

31. Kuehn KD, Ege W, Gopp U. Acrylic bone cements: mechanical and physical properties. Orthop Clin North Am 2005;36:29-39.

32. Kim DG, Miller MA, Mann KA. A fatigue damage model for the cement-bone interface. J Biomech 2004;37:1505-12. 
33. Robinson RP, Lovell TP, Green TM, Balley GA. Early femoral component loosening in DF-80 total hip arthroplasty. J Arthroplasty 1989;4:55-64.

34. Gardiner RC, Hozack WJ. Failure of the cement-bone interface: a consequence of strengthening the cement-prosthesis interface? J Bone Joint Surg $[\mathrm{Br}$ 1994;76-B:49-52

35. Harris WH. Long-term results of cemented femoral stems with roughened precoated surfaces. Clin Orthop 1998;355:137-43.

36. Dowd JE, Cha CW, Trakru S, et al. Failure of total hip arthroplasty with a precoated prosthesis: 4- to 11-year results. Clin Orthop 1998;355:123-36.

37. Langlais F, Kerboull M, Sedel L, Ling RSM. The 'French paradox'. J Bone Joint Surg $[B r] 2003 ; 85-B: 17-20$

38. Kawate K, Ohmura T, Kiyoshi N, et al. Thin cement mantle and osteolysis with a precoated stem. Clin Orthop 1999;365:124-9.

39. Heller MO, Kassai JP, Haas NP, et al. Determination of muscle loading at the hip joint for use in pre-clinical testing. J Biomech 2005;38:1155-63

40. Heller MO, Bergmann G, Deuretzbacher G, et al. Musculo-skeletal loading conditions at the hip during walking and stair climbing. J Biomech 2001;34:883-93.

41. Cristofolini L, Teutonico AS, Monti L, Cappello A, Toni A. Comparative in vitro study on the long term performance of cemented hip stems: validation of a protocol to discriminate between "good" and "bad" designs. J Biomech 2003;36:1603-15.

42. Maher SA, Prendergast PJ. Discriminating the loosening behaviour of cemented hip prostheses using measurements of migration and inducible displacement. J Biomech 2002:35:257-65.

43. Maher SA, Predergast PJ, Lyons CG. Measurement of the migration of a cemented hip prosthesis in an in vitro test. Clin Biomech (Bristol, Avon) 2001;16:30714.

44. Raab S, Ahmed AM, Provan JW. The quasistatic and fatigue performance of the implant/bone-cement interface. J Biomed Mater Res 1981;15:159-82.

45. Nivbrant B, Karrholm J, Soderlund P. Increased migration of the SHP prosthesis: radiostereometric comparison with the Lubinus SP2 design in 40 cases. Acta Orthop Scand 1999;70:569-77

46. Savilahti S, Myllyneva I, Pajamaki KJ, Lindholm TS. Survival of Lubinus straight (IP) and curved (SP) total hip prosthesis in 543 patients after 4-13 years. Arch Orthop Trauma Surg 1997:116:10-13.

47. Bader R, Steinhauser E, Holzwarth U, Schmitt M, Mittelmeier W. A novel test method for evaluation of the abrasive wear behaviour of total hip stems at the interface between implant surface and bone cement. Proc Inst Mech Eng $[\mathrm{H}]$ 2004;218:223-30.

48. Collis DK, Mohler CG. Loosening rates and bone lysis with rough finished and polished stems. Clin Orthop 1998;355:113-22.

49. Cannestra PV, Berger RA, Quigley LR, et al. Hybrid total hip arthroplasty with a precoated offset stem: four to nine-year results. J Bone Joint Surg [Am] 2000;82 A:1291-9.

50. Sylvain GM, Kassab S, Coutts R, Santore R. Early failure of a roughened surface precoated femoral component in total hip arthroplasty. J Arthroplasty 2001;16:141-8.

51. McGrath LR, Shardlow DL, Ingham E, et al. A retrieval study of capital hip prostheses with titanium alloy femoral stems. J Bone Joint Surg [Br] 2001;83-B:1195-201.

52. Agins HJ, Alcock NW, Bansal M, et al. Metallic wear in failed titanium-alloy total hip replacements: a histological and quantitative analysis. J Bone Joint Surg [Am] 1988:70-A:347-56

53. Huo MH, Salvati EA, Lieberman JR, Betts F, Banal M. Metallic debris in femora endosteolysis in failed cemented total hip arthroplasties. Clin Orthop 1992:276:15768.

54. Crawford RW, Evans M, Ling RS, Murray DW. Fluid flow around model femoral components of differing surface finishes: in vitro investigations. Acta Orthop Scand 1999;70:589-95.

55. Crowninshield RD, Jennings JD, Laurent ML, Maloney WJ. Cemented femoral component surface finish mechanics. Clin Orthop 1998;355:90-102.

56. Witt JD, Swann M. Metal wear and tissue response in failed titanium alloy total hip replacements. J Bone Joint Surg [Br] 1991;73-B:559-63.

57. Salvati EA, Betts F, Doty SB. Particulate metallic debris in cemented total hip arthroplasty. Clin Orthop 1993;293:160-73

58. Buly RL, Huo MH, Salvati E, Brien W, Bansal M. Titanium wear debris in failed cemented total hip arthroplasty: an analysis of 71 cases. J Arthroplasty 1992;7:31523.

59. Massoud SN, Hunter JB, Holdsworth BJ, Wallace WA, Juliusson R. Early femoral loosening in one design of cemented hip replacement. J Bone Joint Surg [Br] 1997;79-B:603-8

60. Ebramzadeh E, Norman PL, Sangiorgio SN, et al. Long-term radiographic changes in cemented total hip arthroplasty with six designs of femoral components. Biomaterials 2003:24:3351-63.

61. Kelman GJ, Krakauer JD, Adams SA, Colwell CW Jr. Two- to five-year follow-up of 100 total hip arthroplasties using DF-80 implants. Orthop Rev 1994:23:420-5.
62. Tompkins GS, Lachiewicz PF, DeMasi R. A prospective study of a titanium femoral component for cemented total hip arthroplasty. J Arthroplasty 1994;9:623-30.

63. Charnley G, Judet T, Piriou C, Garreau de Loubresse C. Titanium femoral component fixation and experience with a cemented titanium prosthesis. In: Learmonth ID, ed. Interfaces in total hip arthroplasty. London: Springer-Verlag, 1993:3-10.

64. Hernigou P, Le Mouel S. Do voids in a femoral cement mantle affect the outcome? J Arthroplasty 1999;14:1005-10

65. Eingarter C, Ihm A, Maurer F, et al. Good long term results with a cemented straight femoral shaft prosthesis made of titanium. Unfallchirurg 2002;105:804-10 (in German).

66. Nizard RS, Sedel L, Christel P, et al. Ten-year survivorship of cemented ceramic ceramic total hip prosthesis. Clin Orthop 1992;282:53-63

67. Collis DK, Mohler CG. Comparison of clinical outcomes in total hip arthroplasty using rough and polished cemented stems with essentially the same geometry. $J$ Bone Joint Surg [Am] 2002;84-A:586-92.

68. Sporer SM, Callaghan JJ, Olejniczak JP, Goetz DD, Johnston RC. The effects of surface roughness and polymethylmethacrylate precoating on the radiographic and clinical results of the lowa hip prostheses: a study of patients less than fifty years old. J Bone Joint Surg [Am] 1999;81-A:481-92.

69. Meding JB, Nassif JM, Ritter M. Long-term survival of the T-28 versus the TR-28 cemented total hip arthroplasties. J Arthroplasty 2000;15:928-33.

70. Howie DW, Middleton RG, Costi K. Loosening of matt and polished cemented femoral stems. J Bone Joint Surg [Br] 1998;80-B:573-6.

71. Crawford RW, Gie GA, Ling RSM. An 8-10 year clinical review comparing matt and polished Exeter stems. Orthop Trans 1998;22:40.

72. Middleton RG, Howie DW, Costi K, Sharpe P. Effects of design changes on cemented tapered femoral stem fixation. Clin Orthop 1998;355:47-56.

73. Dall DM, Learmonth ID, Solomon MI, Miles AW, Davenport JM. Fractures and loosening of Charnley femoral stems: comparison between first-generation and subsequent designs. J Bone Joint Surg [Br] 1993;75-B:259-65.

74. Kerboull L, Lefêvre $\mathbf{N}$, Hamadouche $\mathbf{M}$. Infleunce de l'état de surface sur la fixation des implants fémoraux cimentés: étude statistique comparative à 9 ans de deux séries homogèns d'arthroplasties totales de hanche. Rev Chir Orthop Reparatrice Appar Mot 1999;85:117-18 (in French)

75. Morscher EW, Clauss M, Grapiollo G. Femoral components: outcome with the MS-30 stem. In: Breusch SJ, Malchau H, eds. The well-cemented total hip arthroplasty: theory and practice. Berlin: Springer Medzin Verlag, 2005:235-41.

76. Della Valle AG, Zoppi A, Peterson MG, Salvati EA. A rough surface finish adversely affects the survivorship of a cemented femoral stem. Clin Orthop 2005:436:158-63

77. Crawford RW, Psychoyios V, Gie G, Ling R, Murray D. Incomplete cement mantles in the sagittal femoral plane: an anatomical explanation. Acta Orthop Scand 1999;70:596-8.

78. Breusch SJ, Lukoschek M, Kreutzer J, Brocai D, Gruen TA. Dependency of cement mantle thickness on femoral stem design and centralizer. J Arthroplasty 2001;16:648-57.

79. Peters CL, Bachus KN, Craig MA, Higginbotham TO. The effect of femoral prosthesis design on cement strain in cemented total hip arthroplasty. J Arthroplasty2001;16:216-24.

80. Wroblewski BM, Siney PD, Fleming PA. Charnley low-frictional torque arthroplasty in patients under the age of 51 years: follow-up to 33 years. J Bone Joint Surg [Br]2002;84B:540-3.

81. Wroblewski BM, Fleming PA, Siney PD. Charnley low-frictional torque arthroplasty of the hip: 20-to-30 years results. J Bone Joint Surg [Br] 1999;81-B:427-30.

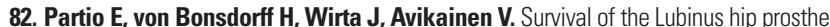
sis: an eight- to 12-year follow-up evaluation of 444 cases. Clin Orthop 1994;303:140-6.

83. Soballe K, Christensen F, Luxhoj T. Total hip replacement ad modum Lubinus: five- to seven-year follow-up. Arch Orthop Trauma Surg 1987;106:108-12

84. Mann KA, Kim BS. Influence of stem shape on fatigue fracture of the cement mantle in femoral hip components. Procs Orthopaedic Research Society, 2000

85. Scheerlinck T, de Mey J, Deklerck R, Noble PC. CT analysis of defects of the cement mantle and alignment of the stem: in vitro comparison of Charnley-Kerboul femoral hip implants inserted line-to-line and undersized in paired femora. J Bone Joint Surg [Br] 2006;88-B:19-25.

86. Kerboull L, Hamadouche M, Courpied JP, Kerboull M. Long-term results of CharnleyKerboul hip arthroplasty in patients younger than 50 years. Clin Orthop 2004;418:112-18.

87. Sangiorgio SN, Ebramzadeh E, Longjohn DB, Dorr LD. Effects of dorsal flanges on fixation of a cemented total hip replacement femoral stem. J Bone Joint Surg [Am] 2004;86-A:813-14.

88. Loudon JR, Charnley J. Subsidence of the femoral prosthesis in total hip replacement in relation to the design of the stem. J Bone Joint Surg [Br] 1980;62-B:450-3.

89. Glyn-Jones S, Gill HS, Beard DJ, McLardy-Smith P, Murray DW. Influence of stem geometry on the stability of polished tapered cemented femoral stems. J Bone Joint Surg [Br]2005;87-B:921-7. 
90. Stolk J, Verdonschot N, Cristofolini L, Toni A, Huiskes R. Finite element and experimental models of cemented hip joint reconstructions can produce similar bone and cement strains in pre-clinical tests. J Biomech 2002;35:499-510.

91. O'Connor DO, Burke DW, Jasty M, Sedlacek RC, Harris WH. In vitro measurement of strain in the bone cement surrounding the femoral component of total hip replacements during simulated gait and stair-climbing. J Orthop Res 1996;14:769-77.

92. Estok DM 2nd, Orr TE, Harris WH. Factors affecting cement strains near the tip of a cemented femoral component. J Arthroplasty 1997;12:40-8.

93. Ling RS, Lee AJ. Porosity reduction in acrylic cement is clinically irrelevant. Clin Orthop 1998;355:249-53.

94. Stolk J, Maher SA, Verdonschot N, Prendergast PJ, Huiskes R. Can finite element models detect clinically inferior cemented hip implants? Clin Orthop 2003;409:138-50.

95. Ahmed AM, Raab S, Miller JE. Metal/cement interface strength in cemented stem fixation. J Orthop Res 1984;2:105-18.

96. Markolf KL, Amstutz HC. A comparative experimental study of stresses in femoral total hip replacement components: the effect of prosthesis orientation and acrylic fixation. J Biomech 1976;9:73-9.

97. Ayers D, Mann K. The importance of proximal cement filling of the calcar region: a biomechanical justification. J Arthroplasty 2003;18(7 Suppl 1):103-9.

98. Gruen TA, McNeice GM, Amstutz HC. "Modes of failure" of cemented stemtype femoral components: a radiographic analysis of loosening. Clin Orthop 1979;141:17-27

99. Ebramzadeh E, Sarmiento A, McKellop HA, Llinas A, Gogan W. The cement mantle in total hip arthroplasty: analysis of long-term radiographic results. J Bone Joint Surg [Am] 1994;76-A:77-87.

100. Arama T, Courpied JP, Postel M. Les complications aseptiques des arthroplasties totales de hanche. In: Postel M, Kerboull M, Evrard J, Courpied JP eds. Arthroplastie totale de hanche. First ed. Berlin: Springer Verlag, 1985:72-88 (in French).

101. Bocco F, Langan P, Charnley J. Changes in calcar femoris in relation to cement technology in total hip replacement. Clin Orthop 1977;128:287-95.

102. Wroblewski BM, Siney PD, Fleming PA, Bobak P. The calcar femorale in cemented stem fixation in total hip arthroplasty. J Bone Joint Surg [Br] 2000;82B:842-5

103. Alter $\mathbf{P}$, Lengsfeld $\mathbf{M}$, Schmitt J. Stress analysis of an anatomically-adapted femur shaft prosthesis (Lubinus SPII). Z Orthop Ihre Grenzgeb 1999;137:129-35 (in German).

104. Andriacchi TP, Galante JO, Belytschko TB, Hampton S. A stress analysis of the femoral stem in total hip prosthesis. J Bone Joint Surg [Am] 1976;58-A:618-24.

105. Ebramzadeh E, Sangiorgio SN, Longjohn DB, Buhari CF, Dorr LD. Initial stability of cemented femoral stems as a function of surface finish, collar and stem size. J Bone Joint Surg [Am] 2004;86-A:106-15

106. Goldberg BA, al-Habbal G, Noble PC, et al. Proximal and distal femoral centralizers in modern cemented hip arthroplasty. Clin Orthop 1998;349:163-73.

107. Blacker GJ, Charnley J. Changes in the upper femur after low friction arthroplasty. Clin Orthop 1978;137:15-23.

108. Ling RS. The use of a collar and precoating on cemented femoral stems is unnecessary and detrimental. Clin Orthop 1992;285:73-83.

109. Carlsson AS, Rydberg J, Onnerfalt R. A large collar increases neck resorption in total hip replacement: 204 hips evaluated during 5 years. Acta Orthop Scand 1995:66:339-42.

110. O'Hara JN, McMinn DJW. Calcar resorption beneath a well-fitting flanged femoral prosthesis. J Arthroplasty 1991;6:147-50.
111. Settecerri JJ, Kelley SS, Rand JA, Fitzgerald RH Jr. Collar versus collarless cemented HD-II femoral prostheses. Clin Orthop 2002;398:146-52.

112. Meding JB, Ritter MA, Keating EM, Faris PM, Edmondson K. A comparison of collared and collarless femoral components in primary cemented total hip arthroplasty: a randomized clinical trial. J Arthroplasty 1999;14:123-30.

113. Ramaniraka NA, Rakotomanana LR, Leyvraz PF. The fixation of the cemented femoral component: effects of stem stiffness, cement thickness and roughness of the cement-bone interface. J Bone Joint Surg [Br] 2000;82-B:297-303.

114. Mann KA, Gupta S, Race A, et al. Cement microcracks in thin-mantle regions after in vitro fatigue loading. J Arthroplasty 2004;19:605-12

115. Joshi RP, Eftekhar NS, Nercessian OA. Osteolysis after Charnley primary lowfriction arthroplasty: a comparison of two matched paired groups. J Bone Joint Surg [Br] 1998;80-B:585-90

116. Star MJ, Colwell CW Jr, Kelman GJ, Ballock RT, Walker RH. Suboptimal (thin) distal cement mantle thickness as a contributory factor in total hip arthroplasty femoral component failure: a retrospective radiographic analysis favoring distal stem centralization. J Arthroplasty 1994;9:143-9.

117. Kawate K, Maloney WJ, Bragdon CR, et al. Importance of a thin cement mantle: autopsy studies of eight hips. Clin Orthop 1998;355:70-6.

118. Hertzler J, Miller MA, Mann K. Fatigue crack growth rate does not depend on mantle thickness: an idealized cemented stem construct under torsional loading. $J$ Orthop Res 2002;20:676-82.

119. Maloney WJ, Jasty $\mathbf{M}$, Rosenberg A, Harris WH. Bone lysis is well-fixed cemented femoral components. J Bone Joint Surg [Br] 1990;72-B:966-70.

120. Jasty MJ, Floyd WE 3rd, Schiller AL, Goldring SR, Harris WH. Localised osteolysis in stable, non-septic total hip replacement. J Bone Joint Surg [Am] 1986;68-A:912-19

121. Langlais F, Howell JR, Lee AJC, Ling RSM. The "French paradox". Hip Int 2002:12:166-8.

122. Skinner JA, Todo S, Taylor M, et al. Should the cement mantle around the femoral component be thick or thin? J Bone Joint Surg [Br] 2003;85-B:45-51.

123. Müller ME. Lessons of 30 years of total hip arthroplasty. Clin Orthop 1992;274:12-21.

124. Delaunay C, Migaud H, Jobin A, et al. Primary total hip replacement in active patients younger than 50 years. Rev Chir Orthop Reparatrice Appar Mot 2005;91:351-74 (in French).

125. Rousseau MA, Le Mouel S, Goutallier D, Van Driessche S. Long-term results of alumina-on-alumina total hip arthroplasty. Rev Chir Orthop Reparatrice Appar Mot 2004;90:741-8 (in French).

126. Hamadouche $\mathbf{M}$, Boutin $\mathbf{P}$, Daussange J, Bolander ME, Sedel L. Aluminaon-alumina total hip arthroplasty: a minimum 18.5-year follow-up study. J Bone Joint Surg [Am] 2002;84-A:69-77.

127. Le Mouel S, Allain J, Goutallier D. A ten-year survival analysis of 156 alumina polyethylene total hip arthroplasties. Rev Chir Orthop Reparatrice Appar Mot 1998:84:338-45 (in French).

128. Osorovitz $\mathbf{P}$, Goutallier D. Clinical and radiographic results of a continuous series of 124 type Ceraver-Osteal hip prostheses with a 9-year survival analysis. Rev Chir Orthop Reparatrice Appar Mot 1994;80:305-15 (in French).

129. Bourne RB, Oh I, Harris WH. Femoral cement pressurisation during total hip arthroplasty: the role of different femoral stems with reference to stem size and shape. Clin Orthop 1984:183:12-16. 